Oration of the College of Community Physicians 2010

\section{Addressing health inequality - then and now}

"Time present and time past

Are both perhaps present in time future, And time future contained in time past (1)"

Eighty three year ago, in September 1927, when pioneers in the field of public health in Ceylon met and formed the Society of Medical Officers of Health, the country was a British colony. The majority of the population were subsistence farmers using traditional technology. The estimated population of the country was 5.3 million, an increase of nearly 164,000 over the previous year, out of which nearly half was due to in migration of South Indian labour. The birth rate for the island was 40 per 1,000 population. The crude death rate (CDR) was 22 per 1000 population and was commented upon by the Registrar General as the most satisfactory since 1884 (2).

160 out of 1000 live born children would not live past their first birthday and infant deaths accounted for $29 \%$ of the total deaths, while under 5 deaths accounted for $47 \%$ of the total deaths. The common causes of infant death were convulsions and "debility", these two conditions accounting for more than half $(51.6 \%)$ the deaths. The Maternal Mortality Ratio was 20 per 1000 live births. Puerperal convulsions (47\%) and septicaemia (35.5\%) accounted for $83 \%$ of deaths.

Only $40 \%$ of the people over 10 years of age were literate and a large disparity was observed between men and women, literacy in men was $56 \%$ compared to 21 $\%$ in women. Life expectancy at birth around this time was 33 years for males and 31 years for females.

The reports of the Director of Health Services of the time record marked regional and ethnic differences in mortality and distribution of disease. It was noted that nearly a fifth of the total mortality recorded in the island were deaths registered on the estates. The infant mortality rate (IMR) on the estates was 239 per 1000 live births compared to urban areas where it was 195 per 1000 live births.

Figure 1 highlights the differences in birth rates and infant mortality rates between the "principal races". The infant mortality among Europeans was 24 per 1000 live births compared to that of Tamils, whose infant mortality rate was 222 per 1000 live births. Tamils here included "permanent inhabitants and immigrant labour" (Ceylon Administrative Reports 1927). The Director of Health Services in his report comments on the infant mortality; "the rate among Europeans s much lower than that which obtains in England and Wales' (2). In 1927, the Registrar General noted that female infants in the age group 3 months to I year recorded a higher mortality compared to male infants; he comments "the increased mortality among females continue to adult life" (2). The difference in IMR between the districts reporting the highest and lowest IMR was 97 per 1000 live births.
L C Rajapaksa

Figure 1: Infant mortality and birth rate by principal races, 1927

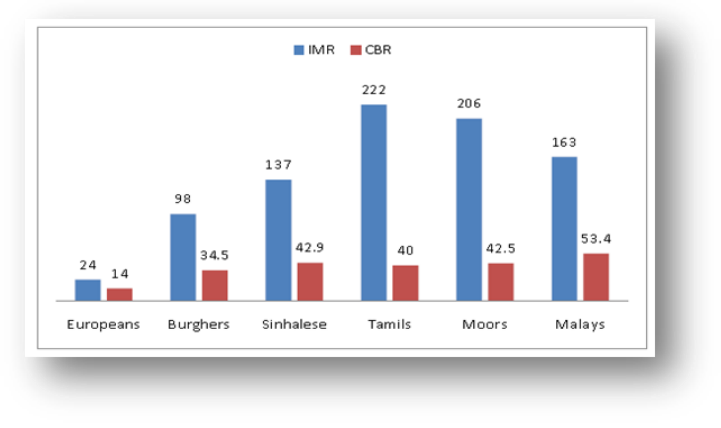

Source: Ceylon Administrative Reports 1927

Malaria, dysentery, leprosy, tuberculosis, bronchitis and pneumonia were the common conditions for which hospital admission were sought. Outbreaks of plague, cholera and small pox occurred from time to time. Malaria was endemic in a large part of the island.

By the time the Society of Medical Officers of Health changed its name to the Ceylon Public Health Association in October 1960, the population had doubled and was 10.5 million. The health indices had shown marked improvements. The population had increased to 10.5 million. Life expectancy had increased to 62.8 years in males and that of the females had surpassed that of men being 63 years. Literacy had improved to $79 \%$ in males and $63 \%$ in females, the difference between the sexes observed in 1927 was $35.2 \%$ and this had more than halved by this time being $16.1 \%$ in 1963 (3).

The infant mortality in 1960 was 52 per 1000 live births, and it was observed that mortality had declined in all subgroups of infancy; the increased mortality seen in female infants over 3 months of age in 1927 had reversed (table 1). The largest reduction in IMR was seen in the districts where the IMR was highest earlier and the difference between the highest and lowest had narrowed to 26 per 1000 live births by 1960 . 
Table 1: Comparison of Infant Mortality rate by sub groups of age in 1926 and 1960

\begin{tabular}{|l|c|c|c|c|}
\hline \multirow{2}{*}{ Age } & \multicolumn{4}{|c|}{ Infant mortality rate per 1000 live births } \\
\cline { 2 - 5 } & \multicolumn{2}{|c|}{1926} & \multicolumn{2}{c|}{1960} \\
\cline { 2 - 5 } & Male & Female & Male & Female \\
\hline Under 7 days & 89.9 & 76.5 & 25.4 & 20.2 \\
\hline 7 days up to 3 months & 50.6 & 47.7 & 17.2 & 15.3 \\
\hline 3 months to under 1 year & 40.5 & 42.9 & 13.4 & 12.7 \\
\hline
\end{tabular}

Source: Ceylon Administrative Reports 1927 and 1960

Prematurity, convulsions, "congenital debility" and infections were the leading causes of death Gastroenteritis was seen among infants over 3 months of age. It was noted that the causes of infant mortality were different on the estates where nearly half of infant deaths were due to prematurity and a further $28 \%$ due to debility (2).

The maternal mortality ratio in 1960 , was 2.6 per 1000 live births, $13 \%$ of the 1926 value. By this time more than half of all births were occurring in government hospitals and $75 \%$ of all births were receiving skilled help at delivery. The main causes of death were Haemorrhage, eclampsia and sepsis. (2).

Many authors have analysed the reasons for these changes $(4,5,6)$ and the factors that have been presented as likely contributors is given below.

1. A key factor was the introduction of universal adult franchise in 1931 accompanied by a limited form of self government. The political changes were reflected in an expansion of services in health, education and rural agriculture.

2.Secondly, the state assumed responsibility for providing health services free of charge.

A structured network of institutions with expansion of services into underserved rural areas, ensured accessibility and a degree of equity. The health unit system emphasised the provision of preventive services at the community level.

From the outset all levels of health care providers were required to be trained according to a prescribed curriculum and to be registered.

3.From the pre independence era the state was committed to expansion of education. At the beginning, the focus was on expanding "vernacular" schools as a means of reaching the rural population. The urban missionary schools which catered to the needs of the colonial administration were also granted assistance. This resulted in a dichotomy of English schools and vernacular schools which to a certain extent is maintained to date. The free education from primary level to tertiary level that came into being after independence, attempted to mitigate this inequity to some extent.
4. The state also intervened in maintaining a minimum consumption level through direct and indirect food subsidy measures. Rural poverty was addressed through improvements in rural agriculture.

5. Another contributory factor to these improvements was the availability of data on a regular and timely basis as well as detailed analytical reports.

6. The traditional values prevalent in society supported and contributed to these changes.

7. Continuing political commitment of post independence governments in spite of slowing economic growth.

It appears that the country has been able to reduce the health equity gap to a considerable extent within a generation through action on the social determinants of health. Given the current morbidity and mortality patterns and the social factors, it is pertinent to inquire if the country can further reduce the equity gap in a generation. It must be noted that a generation now is much longer than the 33 years seen in 1927.

\section{Where are we today?}

The country has undergone a demographic, epidemiologic, and a social transition. Sri Lanka is a low fertility low mortality country with a fast greying population. In this presentation selected instances of unequal distribution of health is examined and where data allows us the socio economic dimensions of the inequality are estimated. The unequal distributions selected for analysis are gender differences in life expectancy at birth and the sector differences in health. Selected mortality data, some aspects of malnutrition, and diabetes mellitus are used in the inequality estimates. 


\section{Gender differences in Life expectancy}

A boy born in 2001 could be expected to live up to 68 years while a baby girl born on the same day could be expected to live up to 76.6 years, an additional 8.8 years. Although females have a biological advantage in mortality over males the difference that is observed appears to be in excess of this. The gender differences in life expectancy show variation between districts. The gap between sexes is highest in Anuradhapura district and lowest in Nuwara Eliya district (7)

When trends in life expectancy are examined it is seen that rate of improvement has been more marked in females compared to males and the gap between them started to widen from around 1971 onwards. The early gains in life expectancy were mainly due to reductions in infant and child death rates. Table 2 shows that there has been improvements in survival after 60 years of age in more recent times and this is a key feature of the mortality transition (7).

Table 2: Expectation of life at age 60 years for men and women 1920-2001

\begin{tabular}{|l|l|l|}
\hline Year & Male & Female \\
\hline $1920-1922$ & 11.5 & 10.6 \\
\hline $1944-47$ & 14.3 & 14.5 \\
\hline 1952 & 16.0 & 14.9 \\
\hline $1962-64$ & 16.6 & 17.0 \\
\hline $1970-1972$ & 16.6 & 17.8 \\
\hline $1980-1982$ & 18.0 & 20.0 \\
\hline $2000-2002$ & 17.2 & 21.3 \\
\hline
\end{tabular}

Source: De Silva 2008

Death rates in those over 45 years show that the rates for males are much higher than the female rates. The excess mortality is seen for causes such as cancers, cirrhosis of the liver, hypertension, heart disease, road traffic accidents and intentional self harm suggesting that life style factors such as smoking and consumption of alcohol may play a role (8)

\section{Sector differences in health}

The lower health indicators observed in the estate sector is an inequity that has been observed in the past and persists still. The social welfare measures that the rest of the population enjoyed from before independence did not reach this group. Historically the health and welfare of the plantation workers was the responsibility of the plantation owners. The immigrant labour on the estates became "stateless" and were disenfranchised following the granting of independence. This anomaly was addressed to some extent following the Sirima-Shasthri pact and rectified completely in recent times. In fact, the group serves as a "control group" in examining the effects of empowerment of people and the social wel- -fare package on health outcomes.

With state ownership of plantations and the formation of social development divisions directly responsible for health and welfare activities, selected direct health interventions have been implemented and these have led to progressive decline in mortality and morbidity rates over the past 30 years.

Access to health services particularly specialised services still remain difficult for those living on estates due to distance, difficult terrain and some limitations of transport.

At present, the estate sector continues to lag behind in most health indicators. The figure 2 shows that that the infant mortality, neonatal and under five mortality are all higher in the estate sector (DHS 1993, 2000, 2006-07). However, the rates of improvement are in excess of improvements recorded in the other sectors.

Figure 2 Comparison of IMR, NNMR and under 5 mortality between sectors

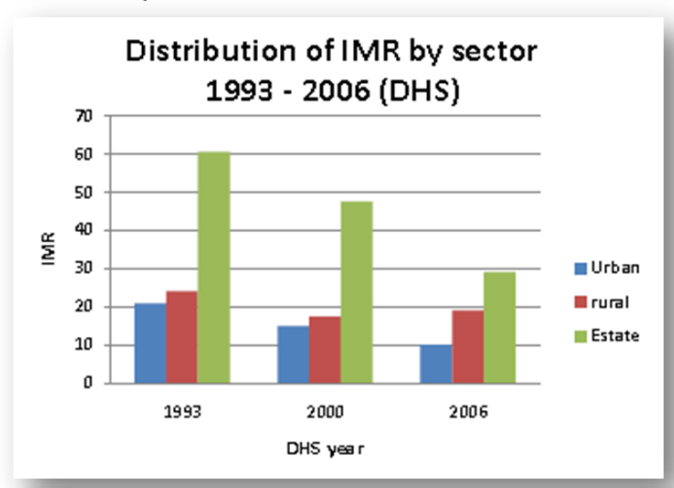

Distribution of $>5$ MR by sector $1993-2000$ (DHS)
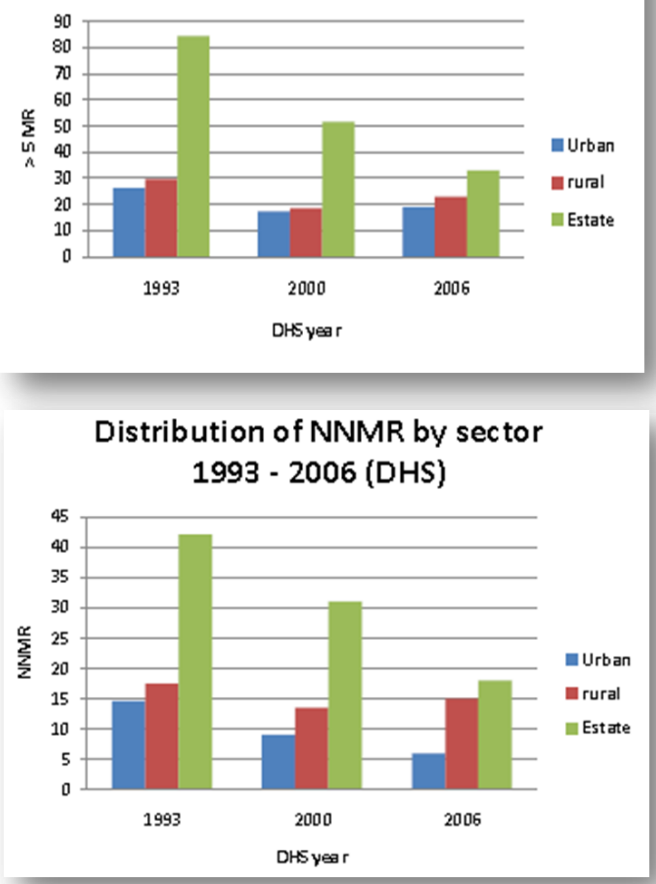

DHS $1993 / 2000 / 2006$

Vol 16, No 1, June 2011 3 
Maternal death ratios are highest in Nuwara Eliya district which has a high percentage of estate population. The district has shown marked improvement in maternal mortality from 168 per 100000 live births in 2001 to 84.4 per 100000 live births in 2005 (8). The estate sector has also shown improvements in use of modern temporary methods of family planning (DHS 1993 and 2006-07)

The sector has also shown marked improvements in educational attainment and there has been investment in social welfare measures such as housing, sanitation, and water supply $(9,10,11)$. Although levels of education and youth employment have improved for both men and women in the estate sector, poverty indicators show deterioration. In this situation it may be important to study the determinants of poverty. It is well known that expenditure on alcohol exacerbates poverty and high rates of alcohol use are reported among both males and females in this sector. Although studies specific to the estate sector are not available it has been shown that in low income settings, expenditure on alcohol and tobacco separately or together accounts for a high proportion of the family income (9).

\section{Mortality indicators}

We are justifiably proud of our achievements in terms of basic health indicators. But as we all know there are district disparities hidden behind these low national figures. Possible socioeconomic factors that may explain the district differentials in health outcomes were examined. Measures of inequality were selected depending on the type of data available.

For examining the district differentials in the selected mortality rates two measures were used; the absolute difference between the highest and lowest values recorded for districts for a given year and the changes in the absolute difference over time. The second inequality measure used was the slope index, which fulfils all requirements of a good measure of health inequality.

The slope index is expressed as a coefficient and it quantifies the relation between the level of health in a particular group and the ranking of that population group according to a deprivation indicator. The coefficient is the change in health level for a unit change in the rank and provides an estimate of the health gap across all the population groups studied.

The socio-economic dimensions examined were; proportion of people in a district who live in GN divisions classified as poor based on the unmet basic needs index (UBNI), poverty head count ratio, poverty gap ratio, proportion of persons below minimum level of dietary energy consumption, proportion of households with sustainable access to what is defined as an improved source of water, proportion of households with access to "improved" sanitation.

\section{District differentials in CDR and IMR}

The district differentials in Crude Death Rate and infant mortality rate have gradually narrowed over time (figure 3).

\section{Figure 3: Absolute differences in CDR and IMR} between districts over time

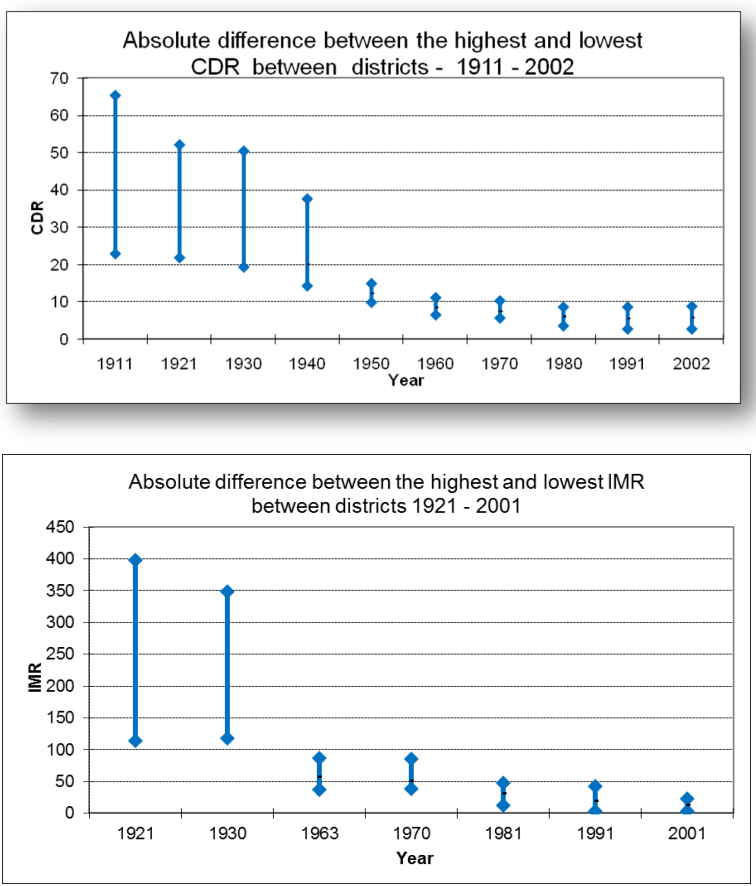

The slope index was calculated for the crude death rate, IMR and MMR using a number of different measures of socio economic status. The coefficients obtained with the different socio-economic indicators were similar and the slope index was small and not statistically significant. What this means is that the mortality differentials between the most and least deprived district explained by the socio economic indicator is only a small fraction of the gap across all districts. A possible explanation may be that health care availability and accessibility are not influenced by the level of poverty in the district and mitigates the influence of poverty on mortality. The district differences in life expectancy at birth were also examined using the slope index. For both males and females the coefficient was not statistically significant. Slope index was also calculated using district mortality rates for selected disease conditions. The diseases examined were breast cancer, cervical cancer, heart disease, homicide, injuries, oral cancer, road traffic accidents, suicides and Tuberculosis. None of these generated statistically significant coefficients. 


\section{Inequity in malnutrition}

Malnutrition data are available from population based surveys and lends itself well to the examination of social determinants. It is observed that in spite of social advances over time and in stark contrast to the other health indicators, unacceptably high rates of maternal and childhood malnutrition persists. I consider malnutrition to be the most important public health problem of the day. This is because of the sheer magnitude of the problem, the effects it has on cognitive development, probable contribution of some indicators to Non Communicable Diseases in later life, the intergenerational effects and loss of productivity. We now also face a double burden of both undernutrition and overweight. The analysis in this presentation is limited to a few indicators of malnutrition, namely low birth weight, maternal body mass index and protein energy malnutrition among children under 5 years of age.

\section{Low birth weight}

According to the last Demographic and Health Survey (2006/07), 17\% of the sample of children studied were born with a weight less than $2.5 \mathrm{Kg}$. The incidence of low birthweight from routine statistics appears to fluctuate around $16 \%-17 \%$ over the past $8-10$ years. A low birthweight of $17.3 \%$ in year 2006 means that 61,735 newborns started life at a disadvantage and are at increased risk of developing morbidities such as type II diabetes, hypertension and dyslipidemia in adult life (12). It has been shown that low birth weight children continue to have lower weights up to 5 years of age, compared to normal weight children (13). Table 3 shows that stunting wasting and underweight are more among those with a low birth weight (14).

Table 3: Prevalence of malnutrition by weight at birth

\begin{tabular}{|l|c|c|c|c|}
\hline $\begin{array}{c}\text { Birth } \\
\text { weight } \\
\text { in } \\
\text { grams }\end{array}$ & $\begin{array}{c}\text { Stunt- } \\
\text { ing \% }\end{array}$ & $\begin{array}{c}\text { Wast- } \\
\text { ing \% }\end{array}$ & $\begin{array}{c}\text { Under- } \\
\text { weight } \\
\text { \% }\end{array}$ & $\begin{array}{c}\text { Anae- } \\
\text { mia \% }\end{array}$ \\
\hline$<2500$ & 32.3 & 20.5 & 39.7 & 26.8 \\
\hline$>=2500$ & 15.6 & 9.9 & 17.1 & 25.1 \\
\hline Odds & 2.1 & 2.1 & 2.3 & \\
\hline
\end{tabular}

Source: Jayatissa and Hosseine, 2010

The prevalence of low birth weight is higher in households with a monthly income less than 14,000 rupees. It is seen that $42 \%$ of Low Birth Weight is concentrated in the two lowest income groups (14). Therefore a focused high risk approach towards improving incomes would pay dividends. Estimations show that if the income of the lowest two income categories were to be improved to the level of the middle income category, the prevalence of low birth weight can be reduced to $14.8 \%$ from the current prevalence of $18 \%$.
The prevalence of Low birth weight is also seen to increase with decreasing education level of the mother. In the case of education, the high risk approach of increasing lower educational levels to secondary level will result in only a small difference in the overall prevalence of low birth weight $(16.1 \%)$. However, by shifting the population educational level so that the population in each education category is shifted to the category immediately above it, the prevalence of low birth weight can be reduced to $14.5 \%$. Here a population approach would be more successful compared to a high risk approach.

The slope index was calculated using the district prevalence in low birth weight from the DHS 2006/07. The coefficients were small and not statistically significant. This shows that the gap in low birth weight between the most and least deprived districts that can be attributed to the poverty indicators examined is only a small percentage of the overall difference.

\section{Body mass index}

Low birth weight is a reflection of maternal health, therefore the differential in BMI across socioeconomic strata and across geographic areas were examined using multiple indicators of socioeconomic status. Demographic and Health survey of 2006-07 reported that $16.2 \%$ of ever married women in the 15-49 year age group had a Body Mass Index (BMI) less than 18.5, while the figure reported for non pregnant women 15-49 years of age was $18.2 \%$ (14). Disaggregating this further by age group, the 2009 study reports an alarming 41\% of women in the 15-19 age category to be underweight (15). The difference in proportion of underweight between the highest wealth index quintile and lowest was $15 . \%$. District prevalence data on low BMI given in the DHS 2006 was used in the calculation of the slope index. The slope index shows that the gap in low BMI between the most deprived and the least deprived districts that can be attributed to the differences in poverty head count ration was $7.3 \%$. The other indicators of poverty such as the proportion of people in a district who live in GN divisions classified as poor based on the unmet basic needs index (UBNI), poverty gap ratio and the proportion of persons below minimum level of dietary energy consumption were similar and had coefficients around $7 \%$. These differences were statistically significant.

\section{Malnutrition in children under 5 years of age} Data on nutritional status of children under 5 years of age are available from a series of national nutrition surveys from 1975 onwards. There are differences between the surveys in respect of the age group studied, districts sampled, and in the case of the first survey the cut off used to identify 
malnutrition. These differences are taken into account in comparisons.

Over the past 30 years there has been a declining trend in stunting and underweight, while little change has been noted in wasting. However, the prevalence of stunting, wasting and underweight remain unacceptably high at $17 \%, 15 \%$ and $21 \%$ respectively (9). There are wide variations in prevalence by sector, district and income groups.

Both DHS data and those from Jayatissa et al (14) show that the richest quintile of the population also have undernourished children. In the later study even in household having incomes above 32, 000 rupees a month $11 \%$ of children under 5 years of age were stunted, $10 \%$ were wasted and $12 . \%$ were underweight. They reported that in the richest assets quintile $10 \%$ were stunted, $8 . \%$ wasted and $12 \%$ underweight. District prevalence of malnutrition from DHS 2006 was used to calculate the slope index for each of the three indicators of malnutrition. It was seen that all the coefficients were small and were not statistically significant.

\section{Non Communicable Diseases}

With the demographic, epidemiologic and social transition, there has been a shift in the mortality and morbidity pattern towards non communicable diseases. According to the Non Communicable Diseases directorate of the Ministry of Health, NCDs accounted for $71 \%$ of all deaths in 2001 and they contribute significantly to disease burden in the country. Comparison of the predicated exponential increase in selected NCDs by Premaratne et al in 2005 (16), with current admission rates to government hospitals show that the current values are within the $95 \%$ confidence limits of the prediction for diabetes and ischaemic heart disease. Hospital admissions for hypertension are below the predicted 95\% confidence limit line. This may be due to early detection of cases and improved management practices which does not necessitate hospitalisation.

Diabetes Mellitus was selected for further analysis because socio- economic data at individual level were available for the Kalutara district from a large representative sample (17). The availability of individual data allowed the use of the concentration index as a measure of inequality. The concentration index like the slope index measures the inequality in the health indicator by the ranking of the socio economic indicator. It is derived from the Gini coefficient and describes the magnitude of the difference. It ranges from -1 to +1 . Larger the absolute value of the concentration index greater the disparity. When there is no inequality, the index is zero. A positive value indicates that the health condition is more concentrated among the lower Socioeconomic group.

The relationship of diabetes mellitus to the level of education, occupation, income and the poverty level of the GN division were examined. Prevalence of diabetes mellitus did not a show a definite relationship with level of education. This is probably because the level of general education per se does not prevent or mitigate disease prevalence unless it provides specific health knowledge leading to change in health behaviour at individual level. A higher prevalence was seen among vendors and manual workers. The prevalence of diabetes was seen to increase with increasing income and living in less deprived GN divisions .

The concentration index was positive in respect of all socio economic variables examined, but the coefficients were small and not statistically significant. This means that the socio-economic indicators examined does not contribute significantly to the inequality in the prevalence of diabetes mellitus.

In summary, except in the case of BMI, the socio economic indicators examined did not appear to contribute significantly to the district differences in morbidity and mortality. The district may not be the ideal unit for analysis, because of high variability within the district, in both the health and the socio economic variables. It may also be that the socio economic indicators used, do not give a true indication of the underlying social dimensions that influence disease. An alternate explanation is that wide accessibility of health services mitigate the social dimensions of health outcomes in terms of mortality. Morbidity could not be examined except for nutritional indicators due to data limitations.

\section{How can we reduce inequity in health?}

If the equity gap in health is to be closed or minimised, then, addressing inequity has to be embedded in and be made central to all development policies and programmes. Their goals and targets must be set and stated in terms of reducing inequality. If such a social justice approach to development is adopted health inequalities can be minimised within a generation.

Measuring and monitoring the gap is essential for addressing inequality. The key issue in attempting this analysis was the difficulty in getting data appropriate for the type of analysis. Inequality analysis needs data on incidence and prevalence of disease as well as on the social indicators collected in the same time frame and for the same geographic unit or population group.

Inequality has to be measured not only in relation to health outcomes but also for life styles and service provision. There is paucity of data on sociological and behavioural perspectives in relation to health. These would assume increasing importance especially in dealing with Non Communicable Diseases. 
Since the underlying causes of ill health and premature death lie mostly outside the health sector, data generated by these sectors are essential for the study of social determinants,. There should be agreement upon the sub national level or groups between which the inequality would be measured as well as the appropriate set of measures for assessing the magnitude of inequality. The current analysis suggests that the district is too large a spatial unit for analysis. It also means that there should be consensus on spatial units and ideally timing of data collection. Comparability issues, procedures for sharing data between sectors, issues of ownership and access have to be addressed. A data directory maintained by a central agency, providing information on what is available, where it is available and the data characteristics would be most useful. Strong and continued political commitment as well as cooperation of many ministries and departments is essential for success of this approach. Towards this end, medical practitioners especially public health practitioners have an important advocacy role.

This is what William Farr did in the $19^{\text {th }}$ century, when he used health statistics effectively for advocacy, for the development of policies towards poverty alleviation and equity in health. I am certain that the health equity gap can be minimised within a life time if we all work towards it with commitment. May this lead us to the goal of equitable human development and wellbeing.

\section{Acknowledgements}

I gratefully acknowledge Dr. Pubudu de Silva for allowing me to use data from his MD thesis.

\section{References}

1. Elliot TS. Burnt Norton ; 2000. [cited 2010 August 22]. Available from: http://www.tristan.icom43.net/ quartets/norton.html )

2. Ceylon Administrative Reports 1927; Colombo 1927

3. Ceylon Administrative Reports 1960; Colombo 1960

4. Marga Institute. Intersectoral action for health: Sri Lanka Study, Colombo: Marga Institute; 1984

5.Gunatilleke, Godfrey. Sri Lanka's social achievements and Challenges in Social Development and Public Policy; a study of some successful experiences; ed. Dharam Aha; UN Research Institute for Social Development, London: Macmillon Press Ltd; 2000

6. Sandaratne N . Economic Growth and Social Transformations, Colombo: Tamarind Publications; 2000

7. De Silva WI. Construction and analysis of national and district life tables of Sri Lanka 2000 - 2002. Colombo: Ministry of Health Care and Nutrition; 2008
8. Annual Health Statistics 2007 [on line]. Colombo: Ministry of Health; 2009. [Cited $2010 \mathrm{Au}-$ gust 10]. Available from: http:// www.health.gov.lk/AnnualHealthBulletin.htm.

9. Department of Census and Statistics [DCS] and Ministry of Healthcare and Nutrition [MOH]. Demographic and Health Survey 2006-07, Colombo: DCS and $\mathrm{MOH} ; 2009$

10.Department of Census and Statistics [DCS] and Ministry of Healthcare and Nutrition [MOH]. Demographic and Health Survey 2000. Colombo: DCS and MOH; 2001

11.Department of Census and Statistics [DCS] and Ministry of Healthcare and Nutrition [MOH]. Demographic and Health Survey 1993. Colombo: DCS and MOH; 1994

12.Barker DJP. Fetal origins of coronary heart disease. BMJ 1995; 311: 171-174.

13.The World Bank (WB). Malnutrition in Sri Lanka: Scale, scope, causes and potential response. Colombo: Human Development Unit, South Asia Region; 2007

14.Jayatissa R, Hossain SMM.'Nutrition and Food Security Assessment in Sri Lanka; Sri Lanka', Medical Research Institute, in collaboration with UNICEF \& WFP; 2010

15.MDG indicators of Sri Lanka: A mid term review 2008. Colombo: Department of Census and Statistics; 2009

16.Premaratne R, Amarasinghe A, Wickramasinghe AR. Hospitalisation trends due to selected non communicable diseases in Sri Lanka 2005-2010, Ceylon Medical Journal 2005 ;50: 2.

17.De Silva P. Social determinants of Diabetes Mellitus in the Kalutara District. [MD Thesis]. Post Graduate Institute of Medicine, University of Colombo; 2010 